Black, and Brown, from their characteristic aspects; the first being snow-covered, while the two others displayed the bare basaltic rocks of which they are composed. In September and October minimum temperatures of $-5^{\circ}$ and $-57^{\circ} \mathrm{F}$. were experienced during two of the journeys.

During a visit to Mount Terror, the eastern slopes of which are terribly wind-swept and bare to the summit, $\mathrm{Mr}$. Skelton made a perilous descent to the sea-ice and was su fortunate as to discover a breeding-place of the Emperor penguin, obtaining several specimens of the young in down, besides photographs and notes. The attacks of scurvy which occurred about this time, brought about by severe work and exposure, were in reality very slight, and their importance has been much exaggerated, all symptoms quickly disappearing when the diet was restricted to seal-meat. Skua gulls, which were also obtained, were found to be excellent eating.

The southern sledge expedition undertaken by the Commander, with Lieut. Shackleton and Dr. Wilson, was carried out entirely on the surface of the great ice-sheet, it being found impossible to reach the land, though it was sufficiently near to allow of observations as regards the bearing and altitude of the different land-masses, as well as sketches and photographs. A remarkable feature seems to be the fiord-like openings by which it is penetrated at various points, though the intervening volcanic masses rise into magnificent ranges of mountains. These openings had the appearance of straits, nothing being seen behind, though the state of the ice-sheet opposite them showed that ice must be pressing out through them. On approaching the land at the furthest south, the ice-sheet was found to be separated from it by an immense chasm, the ice-foot resembling that seen elsewhere at the sea-margin of the lands, and forming a complete bar to further progress. The return journey was rendered difficult by the nature of the surface and the prevalent mist.

The further details supplied of Lieut. Armitage's western expedition show that, after proceeding up one large glacier, lying between precipitous granite mountains, a ridge was crossed by a pass 4000 feet above the sea to a second glacier, which had a general trend from southwest to north-east. Its right-hand branch was ascended to a range of remarkably bare granite mountains, the ice surface being much crevassed. A line of sticks set up during the ascent showed a maximum motion of 3 feet 8 inches in twenty-three days. On gaining a height of 9000 feet a smooth, open snow-covered plain stretched to the westward, its surface being soft, with successive crusts nine inches or a foot apart. There were no sastrugi. The whole horizon to the west was clear and unbroken, and the plain appeared to have a slight fall in this direction. Running streams, 7 feet wide, with occasional pools sometimes a mile in diameter, were seen on the return journey, and Bergschrunds 150 feet deep were found at the base of the mountains. Among the other journeys described, those of Dr. Koettlitz for the investigation of the ice and eskerlike lines of debris in the neighbourhood of the Black and Brown Islands are of most interest.

An interesting complement to the narrative of the British expedition has been supplied by the report of Dr. von Drygalski, leader of the German expedition in the Gauss, which was published as a supplement to the official Reichsanzeiger on July io. It describes the voyage from Kerguelen via $\mathrm{a}$ Heard Island to the supposed position of the non-existent 'Termination Land, the southward advance to a previously unknown land, in the vicinity of which winter quarters were established, the scientific work done at the winter station, and the sledge journeys undertaken during the stay. The Gauss was frozen fast in the ice to the north of this land, the pack there remaining stationary owing to the shallowness of the sea over the "Continental Shelf." Only a few miles to the north it appears to be kept constantly in motion by the heavy swell caused by the westerly storms, which would have seriously impeded the scientific work, besides endangering the ship. From the land rose a bare volcanic peak 1200 feet high, which was named the Gaussberg. The Gauss was set free on February 8 by a strong easterly wind, but was caught again temporarily in a somewhat lower latitude, the final start northward being made on April 8, when the lengthening nights were already making navigation difficult.

\section{THE STRUCTURE OF SPECTRA.'}

THIS paper gives a very lucid account of the structure of various types of spectra, special attention being directed to the work on "series" which has been performed during recent years.

After referring to the splendid work performed by Angström and Rowland in establishing trustworthy tables of standard wave-lengths, the author passes on to the evolution of the definite laws which have been found to govern the distribution of lines in the spectra of many elements, comparing the occurrence of similar definite groupings of lines in the spectrum of a substance to the "harmonics" obtained in acoustics.

In 1863 Mascart found that certain groups of lines of characteristic aspect were reproduced in different parts of the spectrum of the same metal, e.g. he found that similar triplets to the "b" group of magnesium were reproduced in the ultra-violet region of the spectrum of that metal. To-day it is known that altogether there are fourteen such groups in the magnesium spectrum, one in the infra-red, the " $b$ " group and twelve in the ultra-violet.

Similarly in the spectrum of sodium there are twelve such "doublets" as that commonly known as $D_{1}$ and $D_{2}$ in the solar spectrum. If these "triplets" and "doublets" are represented on a scale of wave-lengths, they contract. as they approach the ultra-violet, but if they are represented on a scale of frequencies, the groups of the same metal become identical, and are absolutely superimposable. Similar groups have been found for a large number of metals by Kayser and Runge.

The alkaline metals, like sodium, give a series of "doublets," as also do copper and silver, whilst the divalent metais (Mg, Ca, $\mathrm{Sr}: \mathrm{Zn}, \mathrm{Cd}, \mathrm{Hg})$ give triplets, although some of them, e.g. $\mathrm{Hg}$, are so mixed up with other groups that at first this arrangement is difficult to recognise. Here then we have a simple law, which should be credited to Rydberg, viz. "In the spectra of a large number of elements there exist groups which are reproduced several times, the interval which separates the individual lines of each group (when represented on a scale of "frequencies ') being exactly the same for all the groups."

For the alkaline metals the length of the interval which. separates the doublets varies as the square of the atomic. weights, as is shown in the following table:-

$\begin{array}{lrrrrrr}\text { Metal } & & \begin{array}{c}\text { Atomic } \\ \text { weights } \\ (\boldsymbol{P})\end{array} & & \begin{array}{c}\text { Length of } \\ \text { interval } \\ (\nu)\end{array} & & \nu / \mathrm{P}^{2} \times \mathrm{ro}^{4} \\ { }^{2} \mathrm{Li} & \ldots & 7 & \ldots & - & \ldots & - \\ \mathrm{Na} & \ldots & 23 & \ldots & 0.17 & \ldots & 3.25 \\ \mathrm{~K} & \ldots & 39 & \ldots & 0.57 & \ldots & 3.8 \mathrm{I} \\ \mathrm{Rb} & \ldots & 85 & \ldots & 2.34 & \ldots & 322 \\ \mathrm{Cs} & \ldots & 133 & \ldots & 5.45 & \ldots & 3.09\end{array}$

It was then found that these groups arrange themselves in regular series capable of mathematical expression, and in 1885 Balmer found that on plotting the thirteen lines of hydrogen on a curve which had " $m$ " (the number of the line counting in order from " 3 " in the red to " 15 ", in the ultra-violet) for its abscissa and $\mathrm{N}$ (the frequency) for its ordinate, he obtained a perfectly regular curve which could be exactly expressed by the formula

$$
\mathrm{N}=\mathrm{B} / 4-\mathrm{B} / \mathrm{m}^{2} \text {, }
$$

where $\mathrm{B}$ was a constant. Later, Messrs. Hales and Des. landres discovered sixteen other hydrogen lines in the spectra of prominences and various stars, and it was found that these also might be represented by the above formula

The spectra of metals also arrange themselves in similar series, although the relations are not so easily seen at first, because of the overlapping of the other lines. However, the spectrum of potassium may be taken as an example, and we find that on plotting the lines in a similar manner we obtain three such series, known respectively as "the principal," "the first subordinate," and the "second subordinate" series. In each of these series the brightness of the lines decreases as they approach the more 1 "La Structure des Spectres," by Prof. Ch. Fabry, Marseilles, in the Revue Générale des Sciences, No. 5, March 15.

2 The "doublets" for lithium have not been observed, but if the law is applicable in this case the interval would only be oor 6 , which is too small
to be observed.

No. I 76 I, vOL. 68] 
refrangible end of the spectrum, acting in this respect in a manner analogous to the hydrogen lines. It is found that the potassium curve is exactly similar to the hydrogen, having a horizontal asymptote which corresponds to the fimit of the series. Not only is it similar to the hydrogen curve, but by making two displacements parallel to the coordinates it is found to be superimposable, and both curves may be represented by a generalisation of Balmer's formula, due to Rydberg, as follows :-

$$
\mathrm{N}=\mathrm{A}-\mathrm{B} /(m+\mu)^{2},
$$

where A, B and $\mu$ are constants, B having sensibly the same value as in Balmer's formula.

It is interesting to compare the curves for the various members of the alkaline metals among themselves, when it is seen that both for the "principal" and the "subordinate" series the limits approach the red end of the spectrum in the order of the atomic weights of the metals, as if the greater masses of the atoms caused the frequencies of the vibrations to become less; this same fact becomes obvious when we consider, similarly, the spectra of the other metals classified into their natural groups.

Prof. Fabry next describes the "satellites" which accompany most lines in the several spectra. For an example he takes the spectrum of mercury, which is composed of triplets forming two series, one the "diffuse" and the other the "sharp" ("first subordinate" and " second subordinate" respectively) series of Rydberg. In the "diffuse" series the first element of each group is composed of four lines, the second of three and the third of two, but in the "sharp" series the elements are apparently single lines; this is probably due, however, to the very close proximity of the satellites in the latter series, and in several cases MM. Fabry and Perot have shown sthat, with special apparatus having great resolving power, these lines are of a compound nature, and have come to the conclusion, which at least is probably the correct one, that all the elements of the secondary series are accompanied by satellites. All these satellites appear to share the common property of varying greatly under different conditions of emission (e.g. as temperature, pressure and nature of the electric discharge), and these two observers have shown that, whereas the silver line at $\lambda$ 547.2, which is a satellite of the line at $\lambda .546 \cdot 6$, appears in the spark spectrum in air, it completely disappears when the spark takes place in vacuo. Many metals (e.g. Fe, Ni, Mn) produce spectra so complex that, as yet, it has not been possible to classify them, but this may be done when a means of distinguishing analogous rays is discovered and brought into use.

This latter means may be found when the phenomena first observed by Zeeman, and known as the "Zeeman effect," have received a more complete study. This observer found that if the emission took place in a strong magnetic field, each line was split up into a series of lines symmetrically placed as regards the original line, but differently polarised. Taking the spectrum of mercury as an example, we see that the second subordinate series is made up of triplets, or, as shown above, three separate parallel series of lines, which one may call, in this explanation, " a," "b" and " c " respectively. In the magnetic field the members of the " a" series split up into nine separate lines, four on each side of the original line, some of which are polarised in the plane of the lines of force, the others in the perpendicular plane, but the corresponding line on each side is similarly polarised. In the " $\mathrm{b}$ " series we get lines which are similarly placed as regards the original line, and similarly polarised, but there are only three on each side, the second member on each side in the " a " group having disappeared. Similarly in the " $c$ " series only two extraordinary lines are seen, one on each side of the original, corresponding to the extreme lines in the " a " series.

To the first workers in this field these lines appeared greatly entangled, but, thanks to the labours of Cornu, Michelson, Preston, and more especially Runge and Paschen, order has been evolved from the chaos, and the study of the "Zeeman effect" will, in the future, form a ready means of recognising and determining series, for it has already been proved that "the various lines which go to make up similar series behave in an identical manner when the emission takes place in a magnetic field, and if one represents each line by its 'frequency,' the various nembers, in the same magnetic field, resolve themselves into groups which are strictly superimposable." It is also to be hoped, and even expected, that when the work of Humphreys and Mohler, and others, on the displacement of spectral lines under various conditions of pressure, comes to be further developed, similar laws as to the analogous behaviour of lines in their corresponding series will be evolved.

Prof. Fabry concludes his article with a discussion of the relations which exist between the absorption and emission of the same radiations, taking the example of the telluric absorption assigned to atmospheric oxygen in the solar spectrum as an example for discussion. $\mathrm{He}$ doubts the coincidence of these absorption bands with emission lines in the spectrum of the gas, although, as he points out, experimental means of proving their noncoincidence have yet to be devised.

\section{CONGRESS OF THE SANITARY INSTITUTE.}

THE annual congress of the Sanitary Institute was held at Bradford on July 7-11, under the presidency of the Earl of Stamford.

In his inaugural address Lord Stamford dealt with the history of hygiene, showing how closely the subject was allied to political, social and economic history. In describing broadly the various sanitary questions as they affected the home, factory, and the municipality, the president dealt with the important subject of school hygiene, and pointed out how essential it was that the training schools for teachers should form part of the coordinated system of national education. It should be one of the first requirements in the preparation of the teacher, and also of the inspectors who are appointed to visit the schools, that they should practically understand something of the nature of the child material upon which they are to work, the conditions under which the child can best develop by the teacher's guidance, and the proper use of the appliances provided in modern school buildings.

The sections and conferences to which the papers and discussions of the congress were allotted were presided over by well-known representatives of different sciences connected with hygiene. Prof. Clifford Allbutt, in his address on sanitary science and preventive medicine, brought forward for consideration the question if, within limits, the birth of fewer children under improved conditions may be better in the end than a more voluminous birth-rate of children of which some may be of lower vital capacity, and many less watchfully reared.

Mr. Fitzmaurice, of the London County Council, presided over the section of engineering and architecture, and in connection with some of the large engineering works in which he had been engaged he directed attention to the duty of providing for the medical and sanitary requirements of the large bodies of men temporarily collected for the purpose of carrying out the works, and showed that attention to these requirements was an economic advantage. In works like the Forth Bridge or others in the neighbourhood of large towns the difficulty could be overcome, but in works abroad, such as the Nile reservoir, the problem was a more difficult one, especially as smallpox and typhoid are endemic in the Nile valley, and a large outbreak of either in a camp where 15,000 persons were at times employed would have been disastrous; but by making careful provisions, health conditions were so well maintained that, during the five years the works were going on, there were only four deaths from smallpox and one from typhoid fever. $\mathrm{He}$ also dealt with the health aspects of cheap locomotion to the suburbs, and motor traffic.

Prof. Hunter Stewart, in addressing the section of chemistry, physics, and biology, discussed the spread of and immunity from Asiatic cholera, and referred to Great Britain as the most striking instance of acquired immunity. With a sea traffic from India greater than that of any other European Power, and in constant communication with the Meriterranean ports, with no quarantine and cordon regula tions such as prevailed on the continent of Europe, this country has, since 1866 , known cholera only in the sporadic

No. I76r, vol. 68] 